\title{
Leveling the Field: Gender Inequity in Academia During COVID-19
}

Marwa Shalaby, University of Wisconsin-Madison

Nermin Allam, Rutgers University

Gail J. Buttorff, University of Houston

ABSTRACT This article explores the differential impact of the COVID-19 pandemic on the productivity of male and female academics and whether the ongoing health crisis will exacerbate further the existing gender gap in academia in both the short and long terms. We present early evidence of the pandemic's disproportionate effect on women's research productivity using online survey data supplemented by interview data with regional and international female political scientists. The interviews and survey findings reveal gender disparities in perceived research productivity and service workloads during the pandemic. The results also shed initial light on the pandemic's impact on the research productivity of academics who are parents, especially among women.

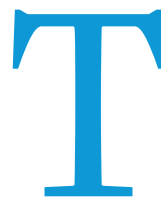

he COVID-19 pandemic transformed our expectations, personal lives, and professional careers in unprecedented ways. As the virus spread, it exposed existing structural and gender inequalities and further deepened others; academia is no exception. Whereas ample evidence exists on the pre-pandemic gender gap in academia (Barnes and Beaulieu 2017; Chávez and Mitchell 2020; Dion, Sumner, and Mitchell 2018; Dolan and Lawless 2020; Hesli, Lee, and Mitchell 2012; Mitchell and Hesli 2013; Teele and Thelen 2017), we continue to learn more on post-pandemic gender disparities from journal submissions data (Wiegard et al. 2020), funded grant proposals, and published research (Flaherty 2020; Kim and Patterson 2020; Kramer 2020). The abrupt shift in instruction modes, advising and mentoring, collaborative work, fieldwork plans, and research dissemination following the mandated lockdowns substantively impacted scholars' productivity, especially women with young children (Breuning et al. 2021). Most recent work has shown that although both men and women with

\footnotetext{
Marwa Shalaby (iD is assistant professor of women and gender studies and political science at the University of Wisconsin-Madison. She can be reached at shalaby2@wisc.edu.

Nermin Allam (iD) is assistant professor of political science and gender studies at Rutgers University at Newark. She can be reached at na587@newark.rutgers.edu.

Gail J. Buttorff is instructional assistant professor and co-director of the Survey Research Institute at the University of Houston Hobby School of Public Affairs. She can be reached at gjbuttor@central.uh.edu.
}

children experienced an increase in time dedicated to childcare, women reported disproportionately larger increases in childcare and decreases in time dedicated to research (Deryugina, Shurchkov, and Stearns 2021).

This article presents early evidence of the pandemic's gendered effect on scholars in the discipline using online survey data and data from semi-structured interviews with female political scientists. Unlike recent work explicating the gender differential effect of the pandemic by focusing on women in academia more generally (Deryugina, Shurchkov, and Stearns 2021) or on a narrow focus of scholars' individual productivity (Breuning et al. 2021), our study uses a mixed-method approach to data collection and analysis. It also provides a more comprehensive view of the effects of the pandemic on scholars' productivity, teaching, and nonresearch-related activities.

Our interviews and survey findings reveal gender disparities in service and perceived research productivity during the pandemic. The results also shed initial light on the pandemic's impact on the research productivity of academics who are parents, especially for women. The data underscore the short-term effects of the pandemic on women's productivity as well as longer-term impacts on their career. Furthermore, data from semi-structured interviews and open-ended survey questions unpack the adverse effects of the pandemic and the gendered processes that enable them. Moreover, the data offer invaluable insights for designing gendersensitive solutions and policies to mitigate the short- and longterm effects of the pandemic on women in the discipline. 


\section{ACADEMIA AS GENDERED INSTITUTIONS}

Academic institutions are predominantly gendered, with women largely marginalized from the academic realm until relatively recently (Ward and Wolf-Wendel 2012). The long-standing and unquestioned presence of male academics has led to gendered norms and expectations that continue to shape the academic milieu. Research in recent decades has shed light on the myriad manifestations of these disparities. Extant work finds that women encounter bias in their teaching evaluations (Chávez and Mitchell 2020) and uneven loads of service and "institutional housekeeping" (Bird, Litt, and Wang 2004; Mitchell and Hesli 2013). Furthermore, studies reveal that female scholars tend to interviews with female political scientists based at US and international institutions. The online survey ${ }^{2}$ was shared with scholars and researchers through academic listservs, personal networks, and social media platforms. ${ }^{3}$ A total of 170 academics in political science, international relations/affairs, and area studies responded to the survey, $54.7 \%$ of whom identified as female and $50 \%$ of whom were parents or guardians of children under the age of 18 . Almost $70 \%$ of respondents hold tenured or tenure-track positions (i.e., assistant, associate, or full professor or the equivalent). 4

To measure research productivity, we examined (1) the change in the number of hours devoted to research, and (2) the ability to submit work for publication compared to

\section{The long-standing and unquestioned presence of male academics has led to gendered norms and expectations that continue to shape the academic milieu.}

have lower research productivity (Teele and Thelen 2017) as well as fewer journal submissions (Dolan and Lawless 2020), citations (Dion, Sumner, and Mitchell 2018), and networking opportunities (Barnes and Beaulieu 2017) compared to their male counterparts. As a result, women are more likely to leave their position and face additional challenges in obtaining tenure-track positions and promotions (Hesli, Lee, and Mitchell 2012).

These issues are compounded further for faculty mothers who often work a "second shift" to keep up with their responsibilities at home (Sallee, Ward, and Wolf-Wendel 2016). Research on motherhood and academia demonstrates that women do more housework and childcare than men (Nakhaie 2009), resulting in a double negative effect on research productivity (Lutter and Schröder 2019), networking opportunities, and promotion.

Early evidence from journal submissions data, social media discussions (Kim and Patterson 2020), and accounts of women's lived experiences (Fazackerley 2020; Lyttelton, Zang, and Musick 2020) suggests both short- and long-term ramifications of the ongoing health crisis. Undoubtedly, the effects of the pandemic will be dissimilar across subfields, research methods, and disciplines. For example, researchers conducting fieldwork and/or "bench-based research" may confront more substantial research delays (Myers et al. 2020). Moreover, the consequences likely will last well beyond the pandemic, further deepening existing gender disparities in academia-especially for female faculty with young children (Windsor and Crawford 2020). Given the likely amplification of present inequalities in academia, the effects on women's productivity and career advancement should be analyzed systematically and adequately addressed with gender-sensitive policies.

The following discussion introduces the data and presents our findings on the impact of the pandemic on political scientists' teaching, research- and non-research-related activities, and the gendered nature of COVID-19's short- and long-term effects. The conclusion describes possible implications of these findings for women's productivity and career trajectories post-pandemic as well as gender-sensitive solutions and policies to mitigate these effects.

\section{DATA AND MEASUREMENT}

We fielded an online survey from June 25 to July 28, 2020 (Shalaby, Allam, and Buttorff 2021) ${ }^{1}$ and conducted 15 semi-structured before the COVID-19 outbreak. We also included questions to capture the different factors that may impact productivity, such as time spent on service, online instruction, and childcare.

\section{EFFECT OF THE PANDEMIC ON RESEARCH PRODUCTIVITY: A GENDERED PERSPECTIVE}

First, we present results on the effect of the pandemic on the number of hours devoted to research. Respondents were asked whether these hours increased, decreased, or stayed the same following the COVID-19 outbreak. As demonstrated in figure $1 \mathrm{~A}$, the productivity of both women and men decreased during the pandemic; however, a larger percentage of women (i.e., $72.8 \%$ versus $61 \%$ ) reported fewer hours devoted to research.

Second, we looked at research productivity in terms of respondents' ability to submit and/or complete work for publication; figure $1 \mathrm{~B}$ shows that both male and female respondents reported a decreased ability. There were less stark gender differences compared to research hours among those reporting a decrease: $76.1 \%$ and $70.1 \%$ of men and women, respectively. It is important, however, to interpret this finding with caution because many factors, including restrictions on travel, data access, and field research, also may have contributed to both men's and women's decreased ability to complete ongoing projects and/or submit work for publication.

Third, increased service and other university, non-research-related responsibilities negatively affect women's productivity because they often incur more service and institutional housekeeping (Bird, Litt, and Wang 2004). Figure $1 \mathrm{C}$ shows the perceived change in respondents' workloads early in the pandemic. As expected, male and female respondents reported an increase in their non-research-related workload; however, more women $(67.4 \%)$ reported an increase in their responsibilities compared to men $(56.6 \%)$.

Fourth, respondents were asked how the transition to online classes impacted their time devoted to teaching. The majority of respondents reported spending more time on online instruction during the first few months of the pandemic (figure 1D): $76 \%$ of women versus $71.2 \%$ of men. In open-ended questions, many respondents called attention to the burden of the abrupt transition to online teaching. One respondent stated that "Online teaching has taken over my life"; another remarked that "Teaching takes twice as much time online, including reassuring students." 
COVID-19 Impact on Research Productivity, Service, and Teaching by Gender

A. Hours Devoted to Research

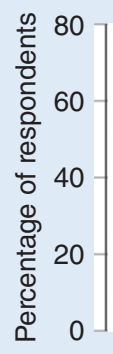

72.8

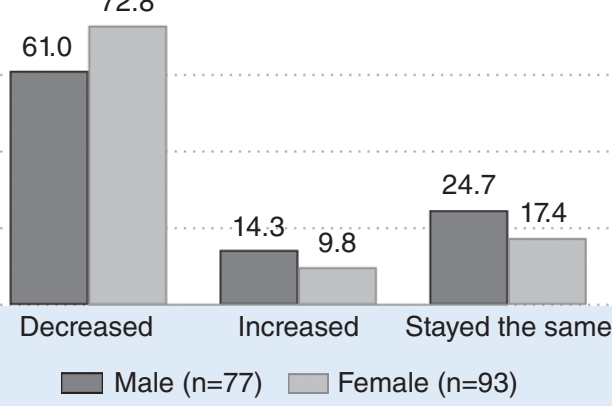

C. Non-Research-Related Workload

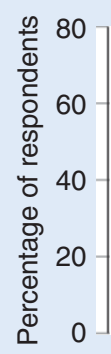

67.4

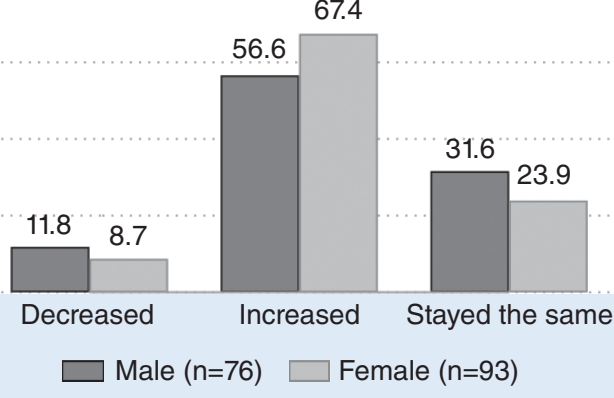

B. Complete and/or Submit Work for Publication
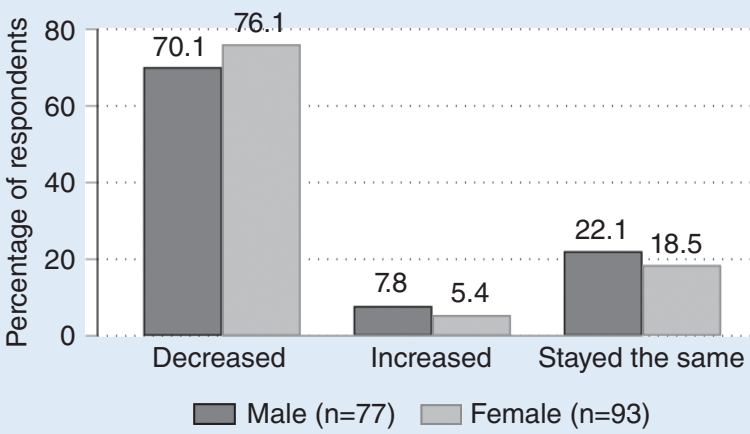

D. Time Spent on Online Teaching

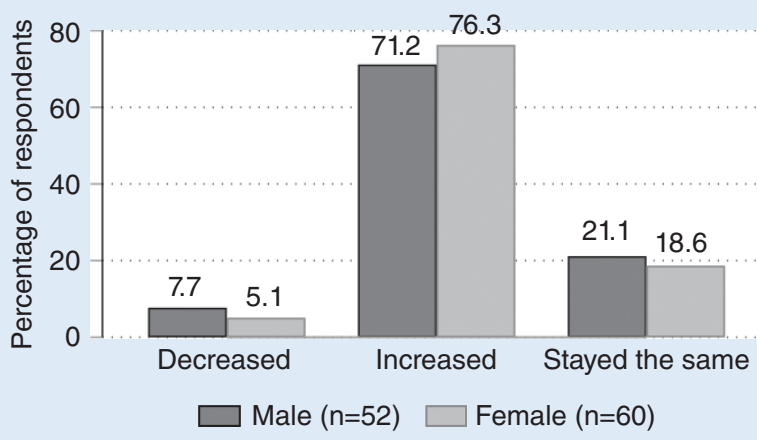

Despite the clear gender differences observed in our data and responses to our open-ended questions, ${ }^{5}$ these patterns are statistically insignificant. This points to the fact that gender may not be the sole explanation for these disparities and that other factors-particularly parenthood-are leading to the observed trends. The following section examines the combined effects of gender, parenthood, and care responsibilities on research productivity and service.

\section{THE BURDEN OF CARE RESPONSIBILITIES}

The COVID-19 outbreak and the closure of schools and childcare providers exacerbated the dual burden of academic and family life for those with young children. Although working from home is associated with more time spent on childcare by both parents, women reported doing more housework (Lyttelton, Zang, and since the COVID-19 outbreak. Consistent with extant work (Deryugina, Shurchkov, and Stearns 2021), the data demonstrate that women were spending 43 hours on childcare, on average, per week compared to 34 hours for men (figure 2). Moreover, $48.9 \%$ of female respondents reported spending more than 40 hours per week, more than double the percentage of male respondents $\left(\chi^{2}=7.14 ; \mathrm{p}=0.068\right)$.

Additionally, figure 3 reveals that significantly more female scholars reported working outside normal business hours to provide childcare $\left(\chi^{2}=4.17 ; \mathrm{p}=0.041\right)$. Female respondents were more likely to take paid or unpaid leave to provide childcare $\left(\chi^{2}=\right.$ 3.oo; $\mathrm{p}=0.083$ ). Yet, despite the increased burden, institutional expectations remained unchanged. Some interviewees described the continued prevalence of a "chilly climate" in their department, in that they felt that they could not be as "candid" or "direct" about

\section{In our survey and interview data, academics with children described the challenge of trying to balance academic responsibilities and increased family demands, with many expressing that any semblance of work-life balance no longer existed.}

Musick 2020). In our survey and interview data, academics with children described the challenge of trying to balance academic responsibilities and increased family demands, with many expressing that any semblance of work-life balance no longer existed.

To discern the negative effect of the pandemic on academic parents, we asked respondents about childcare responsibilities how their professional and personal lives intersect. "It is seen as oversharing," one interviewee explained, "which leads to an attitude in academia, which is unreal, that I can do it all. No biggy. That's not true, but we're just not allowed to say that."

As a result, parents of young children (i.e., under the age of 18) reported spending fewer hours on research $\left(\chi^{2}=11.13 ; \mathrm{p}=0.004\right)$, 


\section{Figure 2}

Hours Spent on Childcare, Excluding Schooling, Since the Outbreak of COVID-19 by Gender

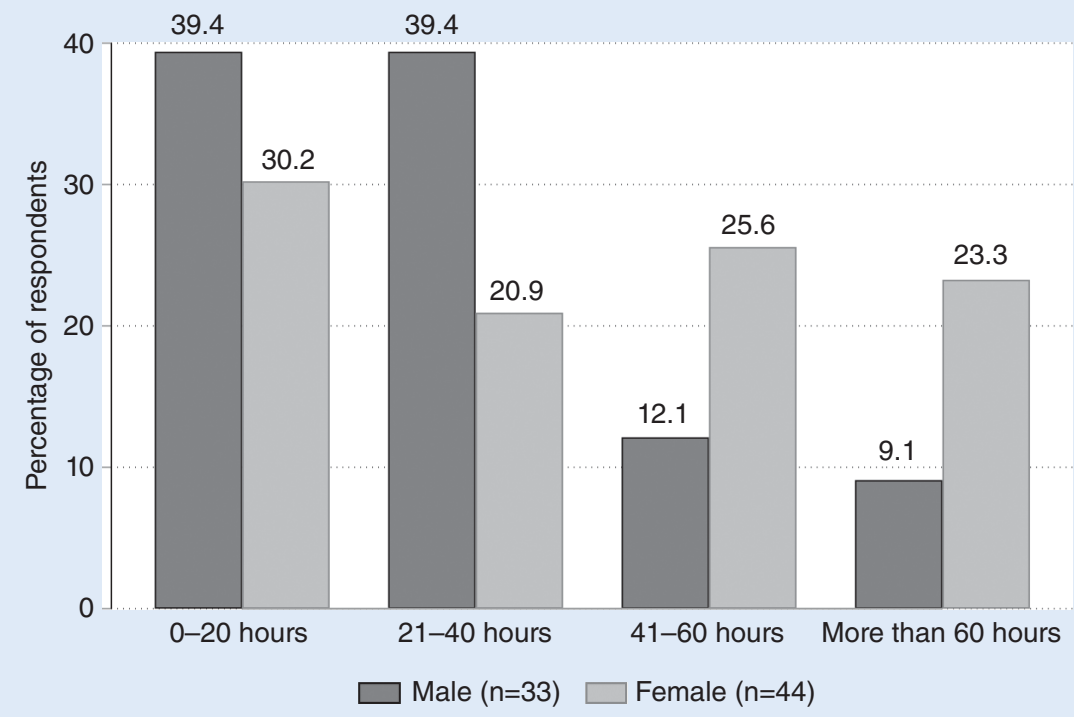

\section{Figure 3}

\section{Childcare Arrangements Since the Outbreak of COVID-19 by Gender}

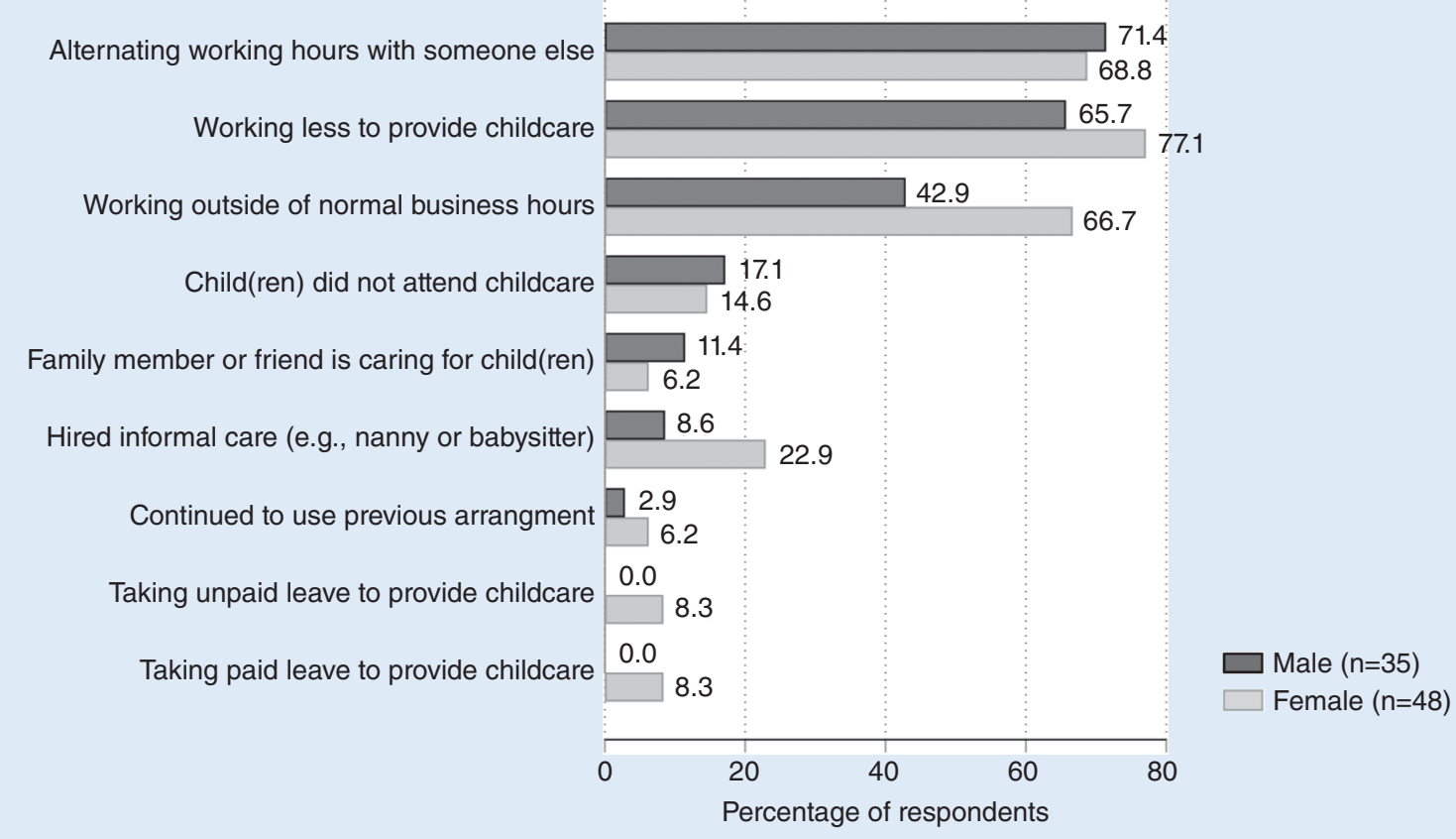

with a higher percentage of mothers reporting a decrease (figure $4 \mathrm{~A}$ ). Of those respondents with young children, $72 \%$ of men and $85.4 \%$ of women reported decreased time devoted to research compared to $51.2 \%$ and $59.1 \%$ of male and female respondents, respectively, without young children. There was a reverse ordering regarding those who reported no change in hours devoted to research: men without young children were the largest percentage reporting no change (31.7\%), and women with young children were the least likely to report no change (8.3\%).

Although the majority of respondents-both those with and without young children-reported a diminished ability to submit work for publication (figure $4 \mathrm{~B}$ ), those with young children, especially women, appear to be particularly disadvantaged. Of the women with young children, $83 \%$ experienced a reduced ability 


\section{Figure 4 \\ COVID-19 Impact on Research Productivity and Service by Gender and Parenthood}

A. Hours Devoted to Research

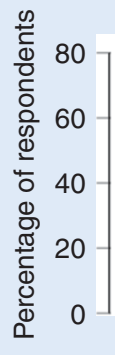

85.4

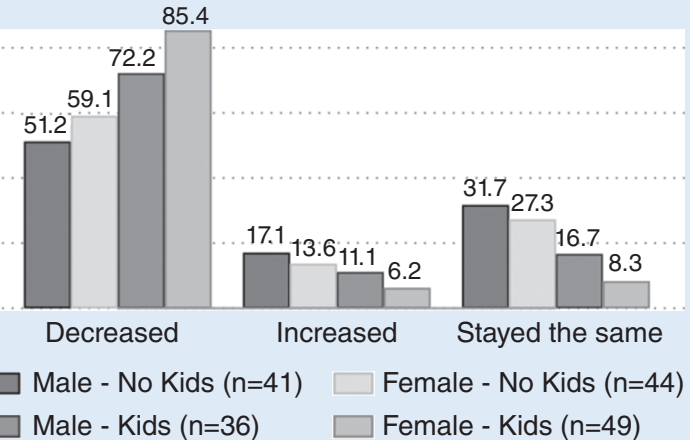

B. Complete and/or Submit Work for Publication

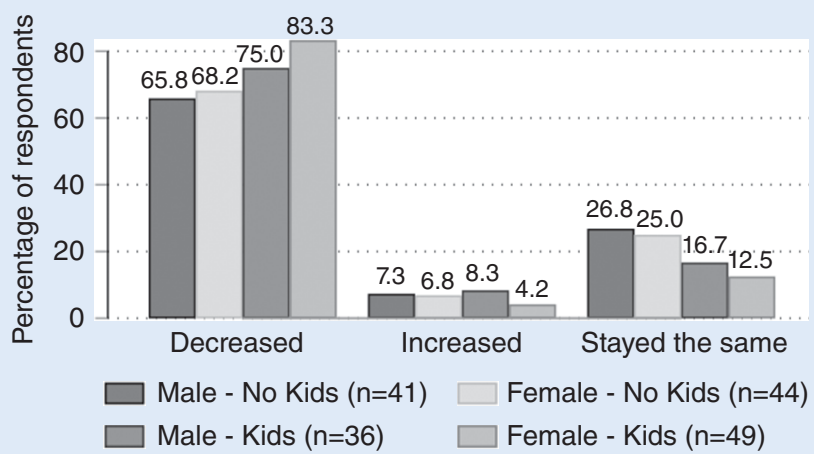

C. Non-Research-Related Workload

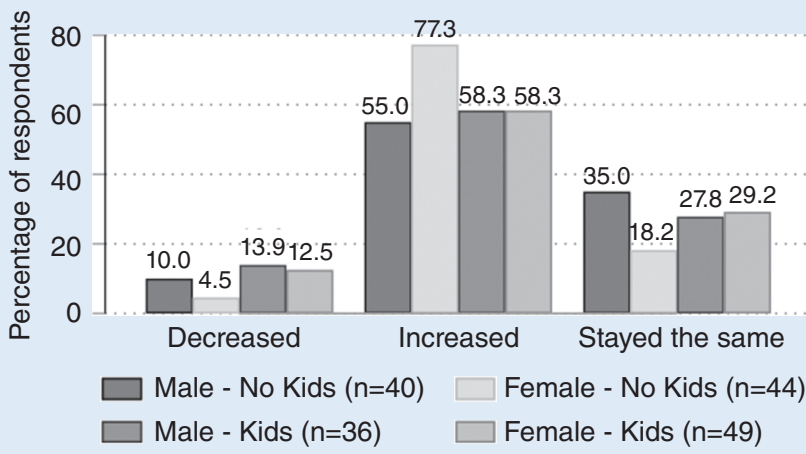

to complete work compared to $75 \%$ for men with young children and $67 \%$ for faculty without young children. ${ }^{7}$

Female faculty, especially female faculty of color, also are often in high demand regarding service, resulting in them assuming a "disproportionate share" of service and mentoring (Mitchell and Hesli 2013; Shalaby, Allam, and Buttorff 2020). Figure ${ }_{4} \mathrm{C}$ demonstrates stark differences: female faculty without children were significantly more likely to report increased service the impracticality of decoupling "gender dynamics from those surrounding parenthood."

\section{LONGER-TERM CONSEQUENCES OF THE PANDEMIC}

Although we are still amid the pandemic and it is premature to fully capture its long-term effects, our survey and interview data expose the likely implications of the ongoing health crisis for women's productivity and career path as well as highlight ways to

\section{If universities continue to apply "male" measures of success in evaluating female academics' promotion and tenure post-COVID, the existing gender gap in academia will only widen.}

-that is, $77.3 \%$ compared to $58.3 \%$ for respondents with young children and $55 \%$ of male faculty without young children. These results are statistically significant. ${ }^{8}$ Female academics, whether or not they have children, face being "mommy-tracked" (Cummins 2005), and this "mother work"-at departmental and university levels-limits their research time for which they subsequently are penalized in tenure and promotion. Results from our survey provide further evidence of how female academics were burdened with domestic-care responsibilities and service demands within their institutions early in the pandemic. As noted by Windsor and Crawford (2020, 276), these results further underscore mitigate them. When asked about the impact of the pandemic, $53 \%$ of respondents agreed that men will have more publications in top journals in the next few years compared to women. Whereas $85 \%$ of respondents either agreed or strongly agreed that women will be worse off than men in academia post-COVID, there was a stark gender gap: $73.3 \%$ of men compared to $94.5 \%$ of women agreed or strongly agreed. ${ }^{9}$

Interviews with female scholars who have young children echoed similar concerns that COVID-19 will have a persistent effect on their research and career. Participants described canceling plans to attend even online conferences and to conduct fieldwork as well as their 
inability to commit to new projects because the future remains uncertain. One interviewee explained why, noting "because we don't know how it's going to be, come September. I can't commit to anything online or in-person." ${ }^{{ }_{10}}$ Although working from home might seem like a better arrangement for parents, this is not always the case. Interviewees cited the need to constantly multitask between work and childcare, and some described the challenges of working in crowded living arrangements.

At the time of the interviews, childcare centers were gradually reopening; however, almost all of the interviewees were not prepared to send their children to daycare and/or school, citing health concerns about infection and transmission. Their concerns highlight an enduring impact of COVID-19: the effects will not be limited to the peak period when childcare and schools were closed; rather, they will continue to shape women's productivity as children remain home until it is sufficiently safe to return.

\section{CONCLUSION}

Our study provides preliminary evidence on the gender differential effects of the pandemic on political scientists' research, teaching, and service. Although much work still is needed to better understand the longer-term impact of the pandemic on productivity and its gendered effects, our study highlights some of the early effects. One limitation of our survey is that it does not quantify the magnitude of the decrease in productivity (i.e., the exact decrease in the number of hours devoted to research and/or the number of submitted publications before and after the pandemic). Future work should discern the magnitude of these effects and assess the difference between the perceived and actual decline in productivity. Although both men and women with young children experienced reduced research productivity early in the pandemic, our findings on reported time spent on childcare and service reveal that women have borne the brunt of the effects.

These findings provide a rather dim perspective on the longterm effects of the pandemic on female academics' careers. If universities continue to apply "male" measures of success in evaluating female academics' promotion and tenure post-COVID, the existing gender gap in academia will only widen. Indicators including publication records, funding, impact factors, and teaching evaluations may carry further bias against women, especially in the post-pandemic landscape (Gouws and Moodley 2020; Htun 2020; Kramer 2020). Funding agencies as well as tenure and promotion committees should consider including more diverse and "holistic" assessments (Gouws and Moodley 2020). For example, evaluation committees should require a COVID-19 impact statement and allow faculty to choose the best productive years in their record (Htun 2020).

Although useful, "one-size-fits-all" policies-such as offering faculty the option of a tenure-clock extension and excluding course evaluations from spring 2020 courses-in fact may present an unequal advantage for men. Whereas the majority of assistant professors in our sample (70.3\%) reported that their institution had offered tenure-review extension, slightly more women were planning to opt out compared to their male counterparts (i.e., $28.6 \%$ of men versus $31.25 \%$ of women). Most of our female interviewees expressed concern that applying for an extension will only inferiorize them further relative to their male colleagues. Some described how their mentors discouraged them from using the extension..$^{11}$
Finally, given the impact of parenthood-on both men and women-it seems crucial now more than ever to bring men into the conversation and to raise awareness among those in decisionmaking and gatekeeping positions in academia about the gendered and differential impact of the pandemic to ensure that gender-sensitive solutions are enacted. ${ }^{12}$ The pandemic will likely exacerbate existing disparities and bring to light new ones, which further underscores the need to address these inequalities in our profession. As one participant eloquently stated, "[i]f the pandemic, if the human loss and the human suffering that we've experienced doesn't make us think about doing this work...I don't know what would." ${ }^{13}$ To achieve this goal, we must continue to engage in meaningful conversations to "level" the playing field by addressing and challenging the gendered institutional climate and expectations.

\section{DATA AVAILABILITY STATEMENT}

Replication materials are available on Harvard Dataverse at https://doi.org/10.7910/DVN/YRSZNE.

\section{SUPPLEMENTARY MATERIALS}

To view supplementary material for this article, please visit http:// dx.doi.org/10.1017/S1049096521000615. -

\section{NOTES}

1. For details on the recruitment process for both the online survey and interviews, see online appendix A.

2. See online appendix B for the survey instrument.

3. We acknowledge that those who most felt the effect of the pandemic were more likely to share their experiences.

4. See online appendix $C$ for more summary statistics on survey respondents for political science and related fields (table $\mathrm{C}_{1}$ ) and the full sample (table $\mathrm{C}_{2}$ ).

5. See online appendix D for responses.

6. Online interview with adjunct professor, May 29, 2020.

7. These results, however, are statistically insignificant after controlling for factors such as academic status and age (see table $\mathrm{C}_{3}$, model 2, in online appendix $\mathrm{C}$ ), which suggests that the pandemic took a toll on everyone's productivity, at least on this dimension.

8. See table $\mathrm{C}_{3}$, model 3 , in online appendix $\mathrm{C}$.

9. See figure $\mathrm{C}_{5}$ in online appendix $\mathrm{C}$.

10. Online interview with adjunct professor, June 16, 2020.

11. Online interview with assistant professor, May 27, 2020.

12. We thank one of the reviewers for highlighting this point.

13. Online interview with instructor, January 15, 2021.

\section{REFERENCES}

Barnes, Tiffany, and Emily Beaulieu. 2017. "Engaging Women: Addressing the Gender Gap in Women's Networking and Productivity." PS: Political Science $\mathcal{E}$ Politics 5o (2): 461-66.

Bird, Sharon R., Jacqueline Litt, and Yong Wang. 2004. "Creating a Status of Women Report: Institutional Housekeeping as Women's Work." National Women's Studies Association Journal 16:194-206.

Breuning, Marike, Christina Fattore, Jennifer Ramos, and Jamie Scalera. 2021. “The Great Equalizer? Gender, Parenting, and Scholarly Productivity During the Global Pandemic." PS: Political Science \& Politics. https://doi.org/10.1017/ S1049096520002036.

Chávez, Kerry, and Kristina M. W. Mitchell. 2020. "Exploring Bias in Student Evaluations: Gender, Race, and Ethnicity." PS: Political Science \& Politics 53 (2): 270-74.

Cummins, Helene A. 2005. "Mommy Tracking Single Women in Academia When They Are Not Mommies.” Women's Studies International Forum 28:222-31.

Deryugina, Tatyana, Olga Shurchkov, and Jenna E. Stearns. 2021. "COVID-19 Disruptions Disproportionately Affect Female Academics.” National Bureau of Economic Research, Working Paper No. 28360. 
Dion, Michelle L., Jane L. Sumner, and Sara M. Mitchell. 2018. "Gendered Citation Patterns across Political Science and Social Science Methodology Fields." Politica Analysis 26 (3): 312-27.

Dolan, Kathleen, and Jennifer L. Lawless. 2020. "It Takes a Submission: Gendered Patterns in the Pages of AJPS." American Journal of Political Science, April 20. https://ajps.org/2020/04/20/it-takes-a-submission-gendered-patterns-in-thepages-of-ajps.

Fazackerley, Anna. 2020. "Women's Research Plummets During Lockdown-but Articles from Men Increase.” The Guardian, May 12. www.theguardian.com/ education/2020/may/12/womens-research-plummets-during-lockdown-butarticles-from-men-increase.

Flaherty, Colleen. 2020. "No Room of One's Own: Early Journal Submission Data Suggest COVID-19 Is Tanking Women's Research Productivity." Inside Higher Ed, April 21. www.insidehighered.com/news/2020/04/21/early-journalsubmission-data.

Gouws, Amanda, and Keymanthri Moodley. 2020. "How Women in Academia Are Feeling the Brunt of COVID-19." The Conversation, May 5. https:// duckofminerva.com/2020/05/journal-submissions-in-times-of-covid-19-is-therea-gender-gap.html.

Hesli, Vicki L., Jae M. Lee, and Sara M. Mitchell. 2012. "Predicting Rank Attainmen in Political Science: What Else Besides Publications Affects Promotion?" PS Political Science \& Politics 45 (3): 475-92.

Htun, Mala. 2020. "Tenure and Promotion after the Pandemic.” Science, June 5 https://science.sciencemag.org/content/368/6495/1075.

Kim, Eunji, and Shawn Patterson. 2020. "The Pandemic and Gender Inequality in Academia." SSRN Scholarly Paper, July 20. Rochester, NY: Social Science Research Network.

Kramer, Jillian. 2020. "The Virus Moved Female Faculty to the Brink. Will Universities Help?" New York Times, October 6. www.nytimes.com/2020/10/06/ science/covid-universities-women.html.

Lutter, Mark, and Martin Schröder. 2019. "Is There a Motherhood Penalty in Academia? The Gendered Effect of Children on Academic Publications in German Sociology." European Sociological Review 36 (3): 442-59.
Lyttelton, Thomas, Emma Zang, and Kelly Musick. 2020. "Gender Differences in Telecommuting and Implications for Inequality at Home and Work." Rochester, NY: Social Science Research Network.

Mitchell, Sara M., and Vicki L. Hesli. 2013. “Women Don't Ask? Women Don't Say No? Bargaining and Service in the Political Science Profession." PS: Political Science \& Politics 46 (2): 355-69.

Myers, Kyle R., Wei Yang Tham, Yian Yin, et al. 2020. "Unequal Effects of the COVID-19 Pandemic on Scientists.” Nature Human Behavior 4:88o-83. https:// doi.org/10.1038/s41562-020-0921-y.

Nakhaie, Reza M. 2009. "Professors, Ideology and Housework." Journal of Family and Economic Issues 30:399-411.

Sallee, Margaret, Kelly Ward, and Lisa Wolf-Wendel. 2016. "Can Anyone Have It All? Gendered Views on Parenting and Academic Careers." Innovative Higher Education 41 (3): 187-202.

Shalaby, Marwa, Nermin Allam, and Gail Buttorff. 2020. "Gender, COVID and Faculty Service.” Inside Higher Education, December 18. www.insidehighered.com advice/2020/12/18/increasingly-disproportionate-service-burden-female-facultybear-will-have.

Shalaby, Marwa, Nermin Allam, and Gail J. Buttorff. 2021. "Replication Data for: Leveling the Field: Gender Inequity in Academia During COVID.” Harvard Dataverse. https://doi.org/10.7910/DVN/YRSZNE.

Teele, Dawn L., and Kathleen Thelen. 2017. "Gender in the Journals: Publication Patterns in Political Science." PS: Political Science \& Politics $50(2): 433-47$.

Ward, Kelly, and Lisa E. Wolf-Wendel. 2012. Academic Motherhood: How Faculty Manage Work and Family. New Brunswick, NJ: Rutgers University Press.

Wiegard, Krista, Debbie Lisle, Amanda Murdie, and James Scott. 2020. "Journal Submissions in Times of COVID-19: Is There a Gender Gap?" Duck of Minerva, May 15. https://duckofminerva.com/2020/05/journal-submissions-in-timesof-covid-19-is-there-a-gender-gap.html.

Windsor, Leah C., and Kerry F. Crawford. 2020. "Best Practices for Normalizing Parents in the Academy: Higher- and Lower-Order Processes and Women and Parents' Success." PS: Political Science \& Politics 53 (2): 275-8o. 


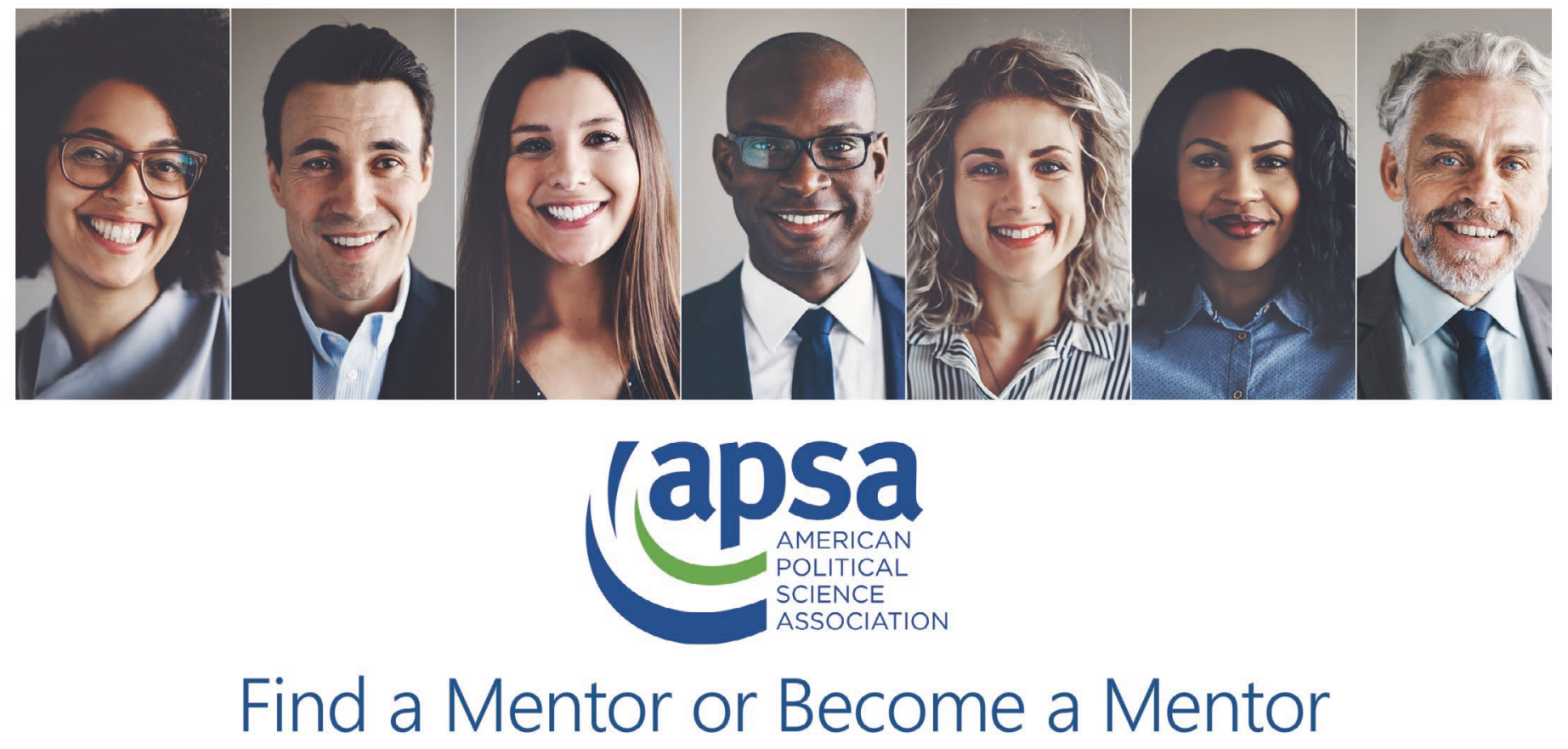

The APSA Mentoring Program is an opportunity for all political scientists to network and share experience, advice and insights about career planning, scholarship, and a variety of professional issues such as:

\section{- Selecting a dissertation committee \\ - Publishing and research \\ - Non-academic careers \\ - Life as junior faculty member \\ - Balancing family and work}

APSA seeks mentors that provide professional advice to undergraduates, graduate students, and junior faculty in the profession, specifically in non-academic careers and international relations, and to mentor Ralph Bunche Scholars (RBSI) and/or APSA Minority Fellows (MFP).

\section{Matching Process}

APSA accepts mentor requests for short-term (one semester) and long-term (one academic year) mentoring. However, matched mentors and mentees are encouraged to continue the relationship beyond the official APSA mentoring period if they find it mutually beneficial.

The APSA staff makes mentor matches twice a year: once at the beginning of the fall semester (for short term and long term matches) and once at the beginning of the spring semester (for short term matches). Matches are made first-come, first-served based on suitability of the match profile and mentor availability.

\section{Apply today! Submit an online application to become} or request a mentor at www.apsanet.org/mentor. 